\title{
Critical Learning Community in a First-Year Engineering Design, Study Abroad Course
}

\section{Dr. Ordel Brown, Northwestern University}

Dr. Ordel Brown is an instructional professor in the McCormick School of Engineering and Applied Science at Northwestern University, where she currently teaches first-year engineering design courses. Her research interests in engineering education include the identification of variables that impact the firstyear experience and the development of strategies to enhance it, retention of underrepresented populations in STEM and global engineering experiences.

\section{Dr. Susanna C Calkins, Searle Center for Advancing Learning and Teaching}

Susanna Calkins, $\mathrm{PhD}$ is the Director of Faculty Initiatives and the Senior Associate Director of the Searle Center for Advancing Learning and Teaching at Northwestern University. She is co-author of two books, Reflective Teaching (Bloomsbury Press, 2020) and Learning and Teaching in Higher Education: The Reflective Professional ( Sage, 2009). She has also co-authored over thirty articles related to conceptions and approaches to teaching, the assessment of learning, program evaluation, mentoring, and has been a co-PI on several NSF grants. She also teaches in the Masters of Higher Education Administration Program at Northwestern.

\section{Dr. Lisa M. Davidson, Northwestern University}

Senior Assessment Associate, Searle Center for Advancing Learning and Teaching 


\section{Work in Progress: Critical Learning Community in a First-Year Engineering Design, Study Abroad Course}

\section{Introduction}

This is work in progress paper highlights the creation and maintenance of a critical learning community within an engineering design, study abroad course. Linked to the UN's 2030 policy agenda outlining inequities in education, health and human services [1], engineering education stakeholders have been mandated to produce engineering graduates with the appropriate attitudes and competencies needed to address such inequities [2]. Consequently, current work in engineering education calls for more socially engaged and enhanced engineering design pedagogy [3], [4], and a shift from the traditional deductive pedagogy and banking concept of education [5], to one that encourages deeper levels of contextual understanding [6]. This pedagogical approach allows students to consider the broader impacts of their work, and acquire professional competencies [7]-[10] that are inculcated and developed in real-world and diverse learning environments. Study abroad contexts, in particular, represent such learning environments. The novel information and opportunities for intercultural exchange stand to cultivate students' professional skills in areas such as intrapersonal (i.e., self-awareness) and interpersonal development (i.e., empathy, reciprocity, respect [11]) and global citizenship [12]).

To provide an opportunity for students to gain competencies in addressing issues related to inequities in social services, we created a study abroad course that focuses on social change through engineering design. Students work on multidisciplinary and multicultural teams, and prototype solutions to social problems associated with inequities in STEM education and/or human services in an international, underserved community. It is designed to move beyond promoting critical thinking to foster the development of critical consciousness--an awareness of the complex interplay between self, others and the world and a commitment to addressing the social issues that may arise from such interplay--in the engineering design process. Specifically, it combines elements of design thinking for social justice [3] with critical pedagogy [5] in the creation of a critical learning community, a unique learning environment which comprises students, instructors and international community partners operating as co-learners in the course. The human-centered focus of design thinking for social justice provides a compelling process for creativity and potential for social change. Critical pedagogy, on the other hand, promotes social change through the critiquing of dominant ideologies, divergent perspectives and societal systems. It centers on consideration of the rich contextual information such as systemic complexity, identity and power dynamics that could enhance or effect social change. The convergence of these two approaches provides a remarkable perspective from which to tackle complex social issues through engineering design, and exceptional support the critical learning community within the study abroad course.

The focus of this initial account is the description of the course structure and assessment methods, highlighting the creation and maintenance of the critical learning community. It explains the underpinning pedagogical theories and overall course design. Then further outlines how structured reflective practices are used to maintain the critical learning community. The reflective practices examine students' self-awareness and positionality (potential impact of 
student's identity on their understanding of and outlook on social issues) in the critical learning community; students' development of critical consciousness; and holistic evaluations of their individual experiences including the broader impacts of their engineering design solutions.

\section{Pedagogical Theories}

Design thinking centers on user needs, and emphasizes collaboration, observation, visualization, and rapid prototyping [13], [14]. The design thinking for social justice methodology goes further to require learners to consider identity and power in the design space [3], and distinctively allows learners to engage as critical beings in the process of social change.

Critical pedagogy requires learners to be both conscious of their positions in the learning environment and how to change it [5]. It requires a decentralization of power in the classroom, and affords an atmosphere in which learners can challenge assumptions and perspectives, adopt a collective orientation and analyze and negotiate power relations [16]-[18] surrounding social challenges.

The similarities between design thinking for social justice and critical pedagogy provide exceptional ways for learners to engage in critical, rational and transformative learning [15], and present a productive context for the development of the critical learning community. In the critical learning community, all stakeholders operate as co-learners and collaborators, and are actively engaged in the construction of knowledge beyond the traditional canned and objective course content. The course content and building of skills are explicitly linked to self-awareness and the awareness of others, and to individual and community values. Within such a learning community, knowledge is viewed as socially constructed, contestable and provisional [18]. These are the processes and mindsets that underlie critical reflection, which is a central activity of the critical learning community. Critical reflection encourages the development of shared meaning, and creates the foundation necessary for the meaningful connection of disparate perspectives, ideas and approaches. Therefore, being critically reflective is essential to being authentically engaged in multicultural and multidisciplinary team environments [18], such as those environments characteristic of many engineering design study abroad courses.

\section{Course Design - Establishing the Critical Learning Community}

(a) Overview: The course -International Development by Design- is a short-term, faculty-led study abroad course designed for earlier undergraduates and open to all majors at Northwestern University. Because the target population for the majority of our institution's engineering global experiences is advanced undergraduates, this course was developed as an earlier undergraduate learning opportunity. Students work closely with Northwestern University faculty, the University of the West Indies, Jamaica, and an international underserved community. Collaboratively, they identify social problems related to inequities in STEM education and/or access to human services within the international underserved community; outline a design challenge; and prototype solutions utilizing only resources that are readily available and easily sourced in the international community. To preserve the ideal faculty to student ratio of faculty-led study abroad initiatives, student enrollment is capped at eight. The instructor and travel-lead is a teaching track faculty in 
the first-year engineering program the Robert R. McCormick School of Engineering and Applied Science at Northwestern University.

Four females and 4 males at the freshman (4), sophomore (3) and junior (1) levels were enrolled. The students are from 5 countries (China, Egypt, Portugal, Rwanda, \& US) and developing expertise across 13 majors. Most students are pursuing double majors in disciplines spanning ME, EE, IEMS, MaDE (Manufacturing and Design Engineering), CS, Asian Languages, Environmental Science, Human Development, Journalism, Physics, Political Science and Psychology. Students work on four-member multidisciplinary teams and across international boundaries to form larger multicultural teams.

The one-credit course spans a total of twelve weeks that includes ten weeks on campus in the spring quarter (late March to mid-June), followed by two weeks abroad in the summer session (first half of July). It is organized in three modules: (i) context analysis, asset assessment \& problem decoding, (ii) prototyping and (iii) implementation \& evaluation. The first two modules are completed in the spring quarter and the third module in the summer session.

(b) Goal and Learning Objectives: The course seeks to cultivate students' abilities to design solutions to complex social problems on an international level. Students completing the course will be able to:

(i) identify and evaluate the complexities of a social problem/design challenge by deconstructing its cultural, historical, political and socioeconomic domains;

(ii) employ design thinking for social justice principles and asset-based methodologies in designing for community capacity building

(iii) demonstrate critical consciousness and cultural humility in working on multidisciplinary and multicultural teams and

(iv) produce clearly articulated, written and oral reports that demonstrate consultation of different types of sources and the critical evaluation of information from these various sources.

(c) Critical Reflection: Critical reflection is a self-regulatory process by which students develop an awareness of how they acquire knowledge, make sense of ideas, and view themselves as individuals and as learners [19]. It involves an awareness of the reasons behind perceptions, emotions, and actions. Critical reflection is a realization that actions are regulated by values and beliefs, and requires a critical appraisal of our assumptions from conscious and unconscious prior learning and their outcomes [20]. As such, critical reflection allows students taking the course to be aware of the context within which they work, requiring them to deeply evaluate their positionality within the design space and how such positionality may influence their perceptions and professional practice. The critical learning community is foregrounded and benchmarked by critical reflection, and is intended to help students transition through self-awareness and positionality within the critical learning community (inward reflection); development of critical consciousness (outward reflection) and awareness and appreciation of the broader impact of their engineering design solutions (backward reflection). A modified Staton design thinking process [15] is used to demonstrate that reflection is facilitated through writing activities which serve as discussion prompts at crucial points throughout the course (Figure 1). 


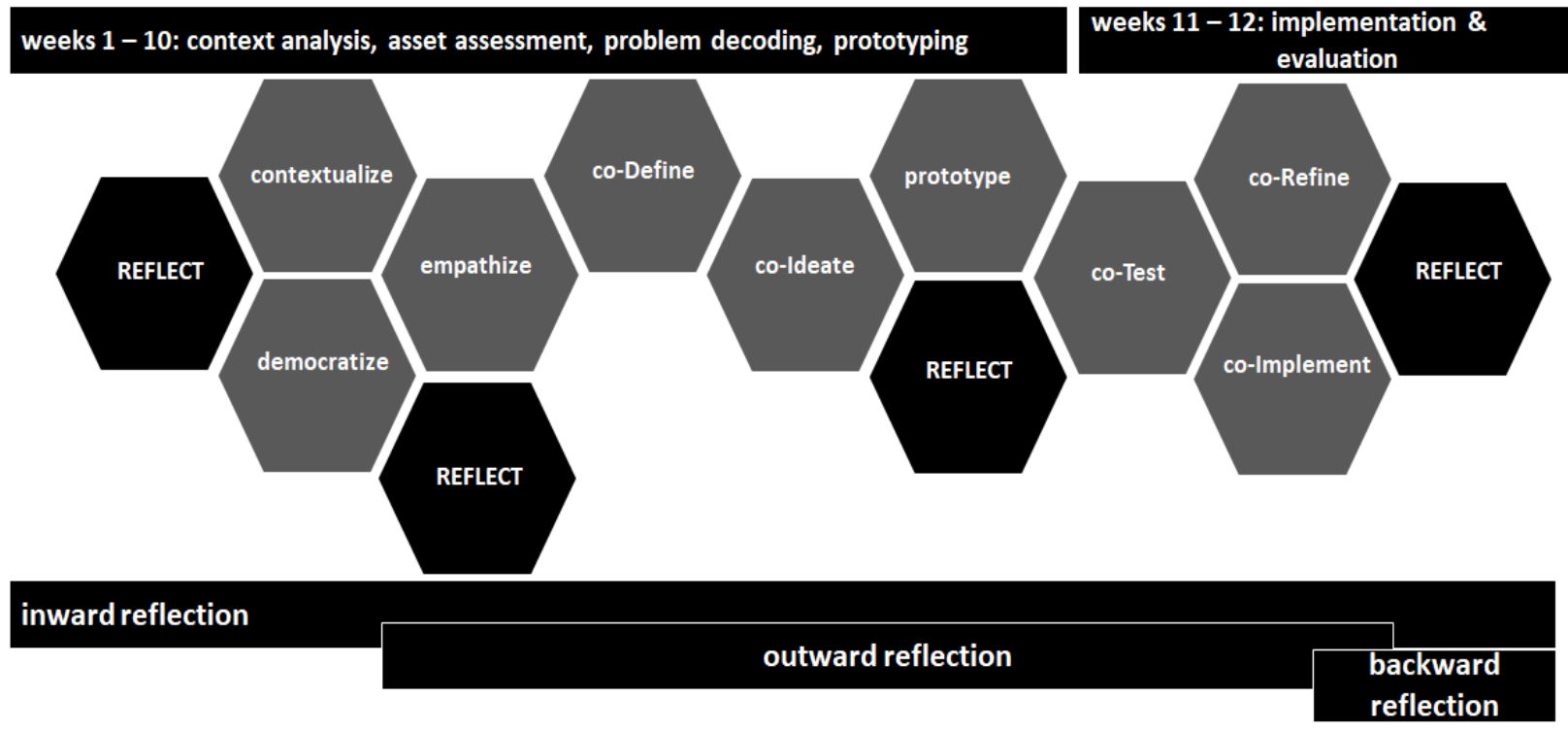

Figure 1 Overview of activities in the critical learning community highlighting key reflection points and types of reflection.

\section{Course Content - Sustaining the Critical Learning Community}

Three structured written critical reflective activities are designed to accompany the student's standard reflection journal and sustain the critical learning community. The initial reflection prompt starts the inward reflection, guided critical incidents analysis prompts outward reflection and photovoice aids backward reflection.

\section{(a) Initial Reflection Prompt - Self-awareness and positionality within the critical learning} community

At the outset of the course, students complete a one-page critical reflection paper designed to capture their motivations for enrolling in the course, their baseline understanding of the challenges that underlie designing for social change, and expectations and initial thoughts about interacting with the international community partners. As part of the prompt students are asked to answer:

-What are the most important things to consider when designing solutions that drive social change?

-In order to ensure quality interactions with stakeholders such as the international project partners and community members, what do you think is most important?

This initial activity provides an opportunity for the students to identify existing constructed knowledge surrounding preferences, assumptions, biases and opinions about all co-learners in the critical learning community. Furthermore, it allows students to evaluate their positionality within the critical learning community and how such positionality may influence their perceptions and engineering design practice.

Later, at the end of the course, they will revisit this prompt, noting where their thinking (knowledge, assumptions, actions, biases etc.) may have changed. Allowing students to reflect 
critically on their prior critical reflections--engaging in metacognition--will allow them to see their own growth in thinking and help them identify gaps, strengths, and areas to develop and or improve.

\section{(b) Guided Critical Incident Analysis (CIA) - Development of critical consciousness}

Critical incidents as described for this course are encounters or experiences that have the potential to significantly influence the direction and progress of the engineering design process in the critical learning community. Critical incident analysis (CIA) evolved out of a multicultural technology development project [22]. It centers relationships among co-learners in and within the context of the design challenge, and encourages students to reflect on the cultural differences [23] and diverse contextual frameworks within which they are operating. Students complete CIAs at two main points in the course. The first is introduced in week 2 and the second one in week 9. In the first CIA students identify and record individual, team and international community partner expectations and perspectives on the design challenge. They highlight areas of overlap, areas of mismatch, and critical incidents. This is expected to enhance communication and enable deeper mutual understanding among co-learners in the process. The second CIA is completed at the point in the quarter when prototyping is almost complete. Building on the framework of contextual focus and relational inclusion in the learning community, students reflect deeper on their interactions with co-learners and the actual steps taken in the design process. They highlight skills, practices and behaviors that have enhanced, encroached on, or eclipsed their design approach or practice in the multicultural setting. Essentially, they will be connecting their contextual understanding of the critical learning community to their design approach and practice. Then, transfer that knowledge and experience to the final steps in the process, when they are fully immersed abroad.

The guided CIAs are individual writing, out-of-class assignments that are followed by in-class discussions on the significance of the analyses. The papers are structured around the three questions [24] given below for CIA \#1:

1. What? - A brief description of:

$\circ$ the most salient emotion(s) experienced so far in your attempt to contextualize and define the design problem

$\circ$ the incident, encounter or activity that evoked the emotion(s)

2. So What?

- How has the experience impacted your assumptions, expectations and perspectives of the co-learners or design process?

3. Now What?

- What specific lessons have you learned?

- What would you do differently if the experience could be repeated?

- Moving forward, how will the experience inform or transform your interactions with the co-learners or your design approach and practice?

CIA \#2 is a slight variation of CIA \#1, and indicative of where the students are in the design process.

1. What? - A brief description of:

$\circ$ the most salient emotion(s) experienced so far in prototyping your design solution

$\circ$ the incident, encounter or activity that evoked the emotion(s) 
2. So What?

- How has the experience impacted your assumptions, expectations and perspectives of the co-learners or design process?

- How has the experience informed or transformed your interactions with the co-learners or your design approach and practice?

3. Now What?

- What specific lessons have you learned?

- What would you do differently if the experience could be repeated?

- How will the experience inform or transform your interactions with the co-learners or your design approach and practice while abroad?

\section{(c) Photovoice - Awareness of the broader impact of their engineering design solutions}

Another critical reflection strategy supporting the critical learning community is photovoice. It is the process by which individuals and groups identify, represent and enhance their communities, by recording the communities' opportunities and challenges through photography [25]. While abroad, students will complete a daily photovoice activity which will be incorporated into the daily debriefing sessions. Using responses from the third question in the Now What section of their second CIA--How will the experience inform or transform your interactions with the colearners or your design approach and practice while abroad?--students identify individual themes for their photos. Students are free to change themes over the two weeks and may only include persons' faces with explicit consent. In each debriefing session, they share the photo that best aligns with their chosen theme. Individually and collectively, the students analyze the shared photos using a technique that stems from the PHOTO [26] protocol, prompted by the following statement/questions:

- Describe your picture.

- What is happening in your picture?

- Why did you take a picture of this/these/her/him/them?

- What does this picture tell us about your collaboration with this community?

- How can this picture provide opportunities for us to improve our collaboration with this community?

At the end of their study abroad each student will have a gallery of photos from which they are required to select ten which will be incorporated in their final presentations on campus. Under the broad topic of People, Perspectives and Practice, students will prepare and deliver the final presentation which includes reflection on their holistic experiences in the course. They will use the photos as aids to process their interactions with co-learners while abroad, and articulate any shifts in personal or professional outlooks, development of notable skills, and further discernment of their project's impact.

\section{Course Evaluation}

The evaluation of this course allows us to understand the extent that this course has actualized the intended impacts. Evaluating various dimensions of the course also stands to inform any 
changes to subsequent course offerings. To evaluate the course, we will collect information to understand students' learning and development, the effectiveness of the course's critical learning community, and community partners' perceptions. In designing the course evaluation, we first understood this as inextricably intertwined with the course's critical theoretical and pedagogical grounding. As such, the evaluation must be culturally relevant and centered on the development and enactment of critical consciousness and cultural humility in the design process.

(a) Students' learning and development: Contextualizing design issues and solutions in increasingly complex ways is a developmental process. Therefore, our evaluation seeks to promote an understanding of students' learning as the course unfolds for both students and the faculty. Our evaluation prioritizes work that students produce--by themselves and collectively-throughout the class. We will collect work from students at key points during the experience that illuminate the development of critical consciousness, asset-based and participatory approaches to design, and effective intercultural exchange.

The course activities--and therefore their evaluation--are informed by the areas of students' development theoretically described in the literature on critical consciousness. The course stands to influence students' abilities to critically reflect (i.e., how they understand social inequalities and intergroup relations), feel a sense of agency and motivation to create change, participate in action toward sociopolitical change, and consider their emotional reactions related to contextualized understandings of themselves and their work [21]. Thus, the course's activities are structured so that students have multiple opportunities to reflect meta-cognitively on their baseline understandings, assumptions, and changing conceptions related to design solutions. The activities also allow students to reflect meta-affectively as they consider their emotional responses to contextualizing and defining their design problem, gain greater levels of awareness, and incorporate diverse perspectives into their work. To evaluate the extent that students are developing in these areas, we are currently developing rubrics that include criteria derived from the theoretical dimensions of critical consciousness described above. We will evaluate students' written reflections at the course outset and conclusion about their understanding (and enactment) of critical consciousness. We will also use the rubrics to evaluate the Critical Incidents Analysis (CIA) assignments, which allow students to reflect on their critical awareness and how they understand their emerging partnerships (CIA \#1) and how they translate their critical awareness into a participatory design processes (CIA \#2).

(b) Critical learning community: Our evaluation also seeks to understand various elements of students' educational contexts that have influenced their learning and development. The critical learning community is an essential aspect of this course design. The required reflection journals allow students--throughout the quarter--to share additional insights related to what it means to understand and integrate diverse perspectives into the design process. They will first share about their procedures with each other, then they will discuss their strategies for collaborating with their community partners. To evaluate the effectiveness of the critical learning community, students will be prompted at various points in the quarter to use the reflection journals to describe any aspects of the community partnership that have influenced how they understand themselves, others, and the communities with whom they will work. Students' reflection journals will be analyzed for themes that emerge.

(c) Community partners' perceptions: Finally, because this course collaborates with international partners, their feedback must be sought in understanding the impact of the course. 
We plan to design a questionnaire that is collaboratively informed by the community partners and faculty. We wish to understand the expectations and priorities of the community partners at the project outset and ask about the extent that these have been actualized through the partnership. Additionally, we seek to understand how our community partners understand the effectiveness of the design projects and ask them to evaluate the learners on these dimensions. Because the development of critical consciousness is so central to the course's learning objectives, we wish to include items that ask the community partners to evaluate the students on particular developmental dimensions (e.g., culturally-relevant understanding of the design context, intercultural competencies). Finally, we will ask community partners to evaluate the usefulness of students' projects and make any recommendations for changes or improvements to subsequent partnerships.

\section{Conclusions and Future Work}

The theoretical and pedagogical underpinnings of the study abroad course yield an excellent framework that supports the structuring of the critical learning community with critical reflection. We anticipate that students will show gains in critical learning and culturally sensitive engagement as they operate within the critical learning community. This expectation is the impetus for future work as we seek to explore the extent to which students develop critical consciousness and cultural humility, and the impact of the various elements of the critical learning community on students' engagement with the design thinking for social justice process. We will share these findings within the context of the outcomes of students' global engineering design projects.

\section{References}

[1] T. U. Nations, "Transforming our world: the 2030 Agenda for Sustainable Development," [Online]. Available:

https://sustainabledevelopment.un.org/post2015/transformingourworld. [Accessed 4 May 2019].

[2] T. A. o. Engineering, "The Engineer of 2020: Visions of Engineering in the New Century," National Academies Press, Washington, D.C., 2004.

[3] T. Brown and J. Wyatt, "Design thinking for social innovation," Ann. Rev. Policy Des., vol. 3, no. 1, pp. 1-10, 2015.

[4] E. Cech, "Culture of disengagement in engineering education?," Sci. Technol. Hum. Val., vol. 39, no. 1, pp. 42-72, 2014.

[5] P. Freire, "Pedagogy of the Oppressed," The Continuum International Publishing Group, London, 1970.

[6] B. J. Ranger and A. Mantzavinou, "Design thinking in development engineering education: A case study on creating prosthetic and assistive technologies for the developing world," Development Engineering, vol. 3, pp. 166-174, 2018.

[7] S. Sheppard, et al. in Educating Engineers: Designing for the future of the field, The Carnegie Foundation, 2008, p. 272. 
[8] I. de los Rios-Carmenado, et al., "Promoting professional project management skills in engineering higher education: project-based learning (PBL) strategy," Int. J. Eng. Educ., vol. 31, no. 1, pp. 184-198, 2015.

[9] A. Alves, et al., "Human Capital and Competencies in Project Management," in Projectbased Learning and its Effects on Freshmen Social Skills, Rijeka, InTech, 2018, pp. 9-26.

[10] B. Jesiek, Y. Shen and Y. Haller, "Cross-Cultural Competence: A comparative assessment of engineering students," Int. J. Eng. Educ., vol. 28, no. 1, pp. 144-155, 2012.

[11] M.E. Engberg, "The influence of study away experiences on global perspective taking," Journal of College Student Development, vol. 54, no. 5), pp. 466-480, 2013.

[12] M.A. Tarrant, D.L. Rubin and L. Stoner, "The added value of study abroad: Fostering a global citizenry," Journal of Studies in International Education, vol. 18, no. 2, pp 141$161,2014$.

[14] C. Dym and et al., "Engineering design thinking," J. Eng. Edu., pp. 103-120, 2005.

[15] B. Staton, et al., "From the Technical to the Political: Democratizing Design Thinking," in From Contested_Cities to Global Urban Justice, Madrid, 2016.

[16] M. Martinez Serrano, et al., "Critical Pedagogy and assessment in higher education: The ideal of 'authenticity' in learning," Active Learning in Higher Education, vol. 19, no. 1, pp. 9-21, 2018.

[17] G. Dehler, M. Welsh and M. Lewis, "Critical pedagogy in the "new paradigm": Raising complicated understanding in management learning," Management Learning, vol. 32, pp. 493-511, 2001.

[18] M. Reynolds, "Towards a critical management pedagogy," in Management Learning: Integrating perspectives in theory and practice, London, Sage, pp. 312-328, 1997.

[19] D. Kember, D. Leung, A. Jones, and A.Y. Loke, "Development of a questionnaire to measure the level of reflective thinking," Assessment and Evaluation in Higher Education, vol. 25, no. 4, 380-395, 2000.

[20] A. Ghanizadeh, "The interplay between reflective thinking, critical thinking, selfmonitoring, and academic achievement in higher education," Higher Education, vol. 74, no. 1, pp.101-114, 2017.

[21] A. J. Thomas, et al., "Assessing critical consciousness in youth and young adults," Journal of Research on Adolescence, vol. 24, no. 3, pp. 485-496, 2017.

[22] M. Welsh and G. Dehler, "Combining Critical Reflection and Design thinking to Develop Integrative Learners," J. Management Educ., vol. 37, no. 6, pp. 771-802, 2012.

[23] S. Vannini, D. Nemer, A. Halabi, A. Sabiescu and S. David, "Critical Incidents Analysis: Mismatching expectations and reconciling visions in intercultural encounters," The J Community Informatics, vol. 13, no. 2, pp. 25-34, 2017.

[24] R. R. Alpers, K. Jarrell and R. Wotring, "Toward a Reflective Practice: Using Critical Incidents," Teaching and Learning in Nursing, vol. 8, pp. 33-35, 2013.

[25] C. Wang and M. Burris, "Photovoice: Concept, methodology, and use for participatory needs assessment," Health Education and Behavior, vol. 24, no. 3, pp. 369-387, 1997.

[26] J. Horwitz, "Photovoice as a critical reflection methodology," in Agency through teacher education: Reflection, community, and learning, Lanham, Rowman \& Littlefield Publishers, 2012, pp. 15-24. 